\title{
Transpterygoid Stent Placement for Management of a Recurrent Infratemporal Fossa Epidermoid Cyst: A Technical Note
}

\author{
Tarik Ibrahim ${ }^{1}$ Paul D. Ackerman ${ }^{1} \quad$ Kevin C. Welch ${ }^{2} \quad$ Vikram C. Prabhu ${ }^{1}$ \\ ${ }^{1}$ Department of Neurological Surgery, Loyola University Medical \\ Center, Maywood, Illinois, United States \\ 2 Department of Otolaryngology, Loyola University Medical Center, \\ Maywood, Illinois, United States

\begin{abstract}
Address for correspondence Vikram C. Prabhu, MD, FAANS, FACS, Department Neurological Surgery, Loyola University Medical Center, 2160 South First Avenue, Maywood, IL 60153, United States
\end{abstract} \\ (e-mail: vprabhu@lumc.edu).
}

J Neurol Surg Rep 2013;74:123-128.

\section{Introduction}

Epidermoid cysts (ECs) are benign congenital cysts that typically develop from misplaced stratified squamous epithelium during neural tube closure. They are most commonly encountered in the cerebellopontine angle, the fourth ventricle, and the sellar region. ${ }^{1-3}$ They are slow-growing lesions that are often intertwined with or encase critical vascular and neural structures complicating surgical removal. They are frequently asymptomatic but occasionally cause mass effect, cranial neuropathies or neuralgias, or seizures, and they are not often symptomatic before the age of 20 years. ${ }^{4-6}$ Rarely, cases of cyst rupture causing granulomatous meningitis or hemorrhagic infarction have been described. ${ }^{7,8}$ They are generally benign, but rare case reports of malignant transformation of an EC into squamous cell carcinoma are noted. ${ }^{9}$

ECs cysts are typically hypointense on T1-weighted and hyperintense on T2-weighted magnetic resonance imaging (MRI) with a variable, although generally minimal, degree of peripheral enhancement. ${ }^{1,10-12}$ Diffusion-weighted imaging

received

November 14, 2012

accepted after revision

August 15, 2013

published online

November 6, 2013 and fluid-attenuated inversion recovery sequences may also be helpful in narrowing the differential diagnosis because ECs are almost always hyperintense on both of these sequences. ${ }^{13-16}$ On gross inspection, the thin, translucent, welldefined capsule of an EC has a characteristically "pearly" appearance and, under light microscopy, the capsule appears as sheets of keratin interposed with anucleate squamous epithelium. $^{3,9}$

Treatment of symptomatic ECs is surgical resection, and gross total resection may be curative. ${ }^{17-19}$ Following surgery, close surveillance is essential because ECs may recur or residual cyst components may regrow; the exact incidence or the factors that predispose ECs to recur are not known. Repeat resection, if feasible, is considered the standard of care for a recurrent EC; the role of adjuvant chemotherapy or radiation remains unclear given the benign nature of these lesions. ${ }^{20}$ However, the proximity to or involvement of critical neural and vascular structures, particularly in the setting of postoperative scar tissue, may complicate repeat surgical excision. (c) 2013 Georg Thieme Verlag KG Stuttgart · New York
License terms

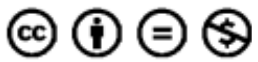




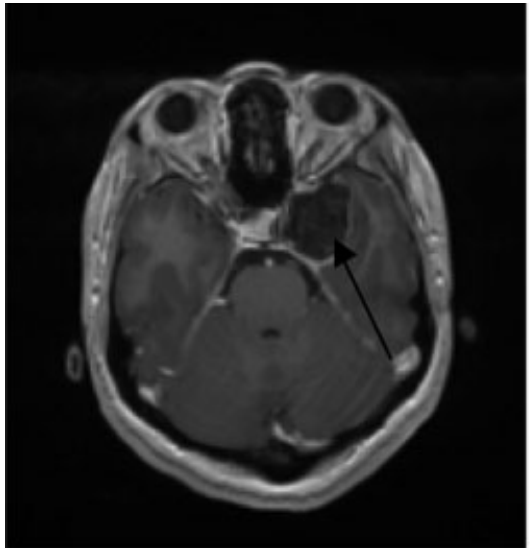

a) Axial $\mathrm{T} 1+$

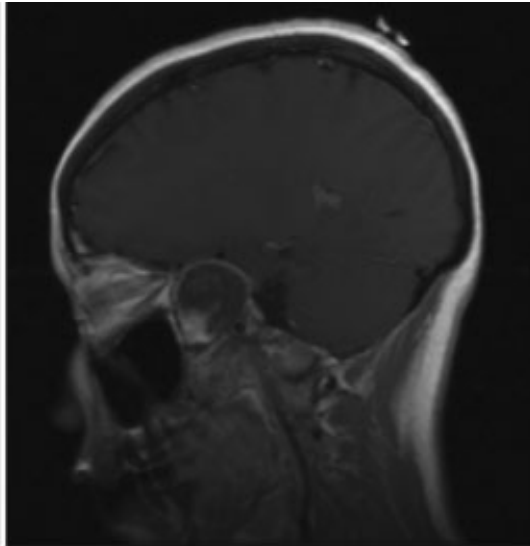

b) Sagittal T1+

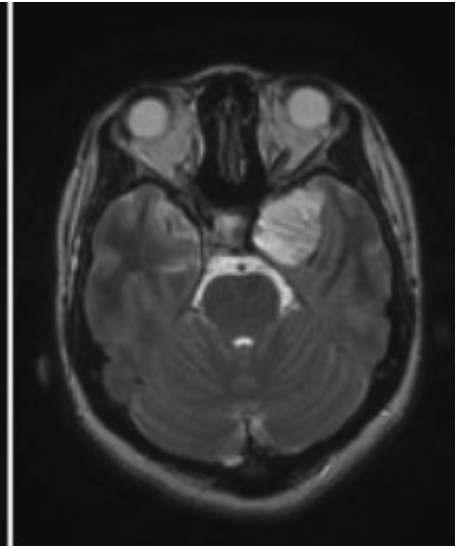

c) Axial T2

Fig. 1 Preoperative magnetic resonance imaging. (A) Axial T1 postgadolinium infusion image demonstrates a heterogenously enhancing lesion adjacent to the mesial temporal cortex extending into the cavernous sinus (arrow). (B) Sagittal T1 postgadolinium infusion image shows extension of the lesion to the infratemporal fossa. (C) Axial T2 image reveals the extra-axial location of this homogeneously hyperintense lesion with focal compression of the adjacent temporal cortex.

Endoscopic approaches to anterior cranial base pathology have gained universal acceptance. Extending these approaches to lesions of the middle cranial and infratemporal fossa are also described with success. ${ }^{21}$ The advantage of these approaches is that they eliminate the risk associated with repeat craniotomy, and in the case of an EC, they permit an intralesional debulking and removal that avoids contact with the neural and vascular structures intimately associated with the cyst wall, as done in the case presented here. In addition, we describe a novel technique using an implanted silastic stent that maintained the patency of the transpterygoid pathway communicating the cyst contents to the maxillary sinus that has allowed effective management of recurrent cyst components with minimal morbidity.

\section{Case Report}

A 37-year-old Hispanic woman presented with daily headaches, occasional dizziness, and intermittent blurry vision in her left eye. On examination, she was noted to be neurologically intact with normal visual acuity and no visual field deficit to confrontation. MRI demonstrated a $3.0 \times 2.6 \times 2.1 \mathrm{~cm}$, peripherally enhancing, solid-cystic lesion in the inferomedial aspect of the left temporal lobe. The solid component of the tumor appeared to infiltrate the cavernous sinus and to encase the internal carotid artery. There was no adjacent edema, calcification, or hemorrhage (-Fig. 1).

The patient underwent an uncomplicated left pretemporal craniotomy and zygomatic osteotomy for near-total resection of the lesion. The portion in proximity to the cavernous sinus was left behind. Frozen section and permanent pathology studies confirmed the lesion to be an EC (-Fig. 2). The patient was neurologically intact postoperatively, and MRI on postoperative day 1 revealed a good resection with some residual tumor in the cavernous sinus (-Fig. 3). With a normal neurologic examination and no evidence of mass effect from the residual tumor, no adjuvant therapy was considered.
Twenty months after the initial operation, surveillance cranial MRI revealed regrowth of the cystic component of the EC into the infratemporal fossa with the anteromedial aspect of the EC abutting the maxillary sinus (-Fig. 4). Upon identifying the recurrence, the patient was offered an endoscopic transpterygoid approach for drainage and resection of the recurrent lesion. A wide maxillary antrostomy and complete sphenoethmoidectomy with posterior septal resection were performed. Using the bi-nostril four-handed technique, the infratemporal fossa was dissected until the tumor capsule was identified, widely exposed, and opened. The contents of the EC were completely evacuated. This repeat endoscopic approach avoided the previous cranial surgical site and created a means of external drainage into the maxillary and sphenoid sinuses to allow any recurrent cyst material a route for egress.

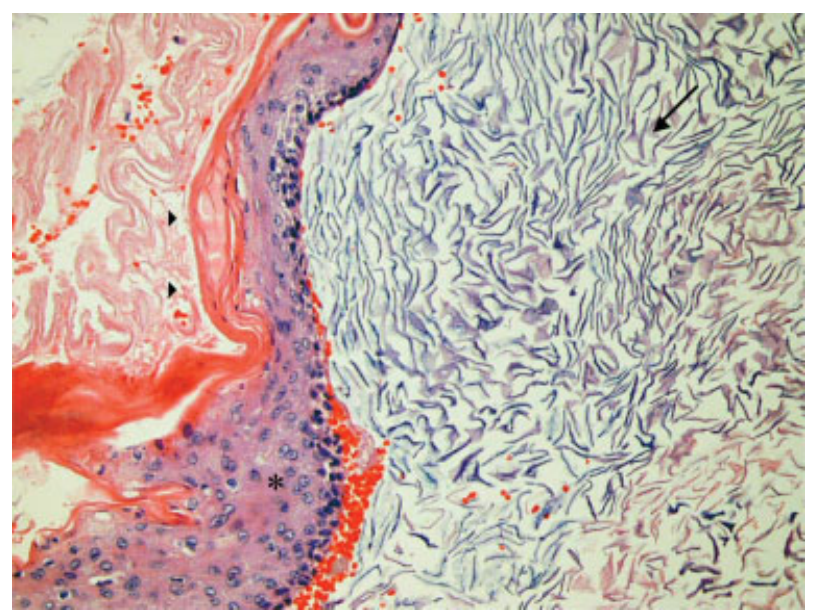

Fig. 2 Pathology. Cyst wall lining (asterisk) composed of simple stratified squamous epithelium supported by an outer layer of collagenous tissue (arrowheads) and exfoliated, keratinized anucleate squamous debris (arrow) within the cyst. Findings were consistent with an epidermoid cyst. 


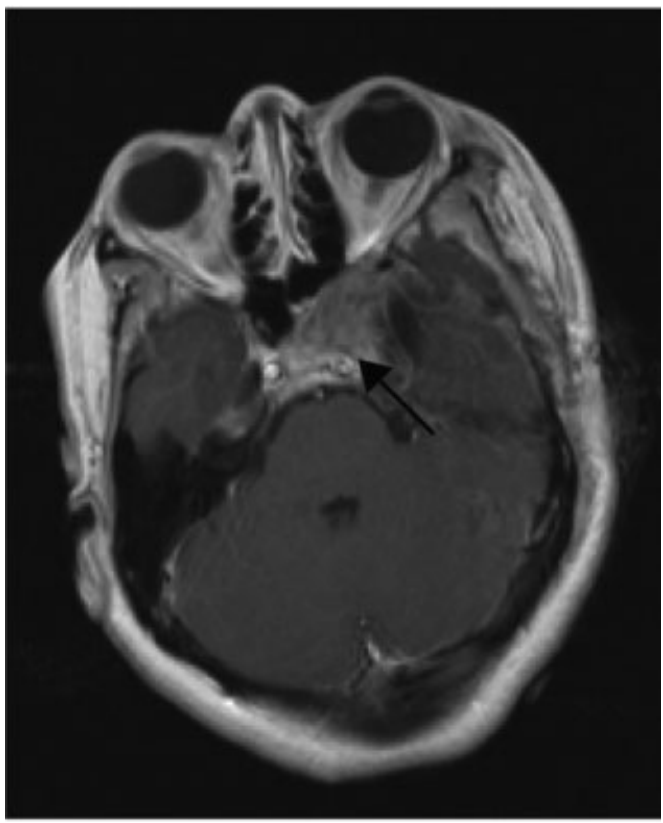

Axial T1+

Fig. 3 Postoperative axial T1 postgadolinium infusion image shows good resection of the mesial and infratemporal portion of the epidermoid cyst with minimal residual cyst noted within the cavernous sinus (arrow).

The patient did well for several months, but she subsequently developed acute bacterial rhinosinusitis that, despite treatment with culture-directed therapy, resulted in stenosis of the transpterygoid drainage pathway into the maxillary and sphenoid sinuses. She remained clinically stable with minimal symptoms, but a follow-up cranial MRI demonstrated recurrence of the EC in the infratemporal fossa. She was taken back to surgery and underwent a maxillary antrostomy and endoscopic reopening of the transpterygoid pathway. On this occasion, the procedure was supplemented with place- ment of a silastic stent communicating the EC in the infratemporal fossa into the maxillary sinus ( $\mathbf{- F i g . ~ 5 )}$ ). The silastic stent has provided excellent endoscopic access into the infratemporal fossa for periodic drainage and debridement of recurrent cyst material, in the outpatient setting with no morbidity. The patient is now more than 38 months out from her initial open cranial surgery and is doing well without focal neurologic deficits. She returns periodically to the outpatient clinic for maxillary sinus debridement and cyst drainage.

\section{Discussion}

ECs are benign congenital cysts best treated with gross total resection. In this instance, the lesion was located in the anteromedial aspect of the middle cranial fossa, and the pretemporal approach allowed adequate exposure facilitating a good initial resection. The pretemporal approach, originally described by de Oliveira et al to provide access to the interpeduncular cistern and petroclival region, combines the advantages of a pterional approach and a subtemporal approach. ${ }^{22}$ Sacrificing the bridging veins from the temporal pole to the sphenoparietal sinus allows posterior displacement of the temporal lobe, as done in this case, and access to the anteromedial aspect of the middle cranial fossa. A near-total excision was achieved, but the portion of the tumor that appeared to invade the cavernous sinus and to abut the internal carotid artery was left inviolate to avoid neurologic deficits.

Incompletely resected ECs may regrow, and repeat surgical excision is usually considered before any other adjuvant therapy. The benign nature of the lesion makes the use of external-beam radiation therapy and chemotherapy less attractive options. A repeat resection via a pretemporal craniotomy was considered, but after a careful discussion of the details of surgery and risks, the patient was reluctant to proceed with another open cranial procedure. Given that the recurrent cyst had a representation into the infratemporal fossa, the option of an endoscopic transnasal, transmaxillary, transpterygoid approach was considered.

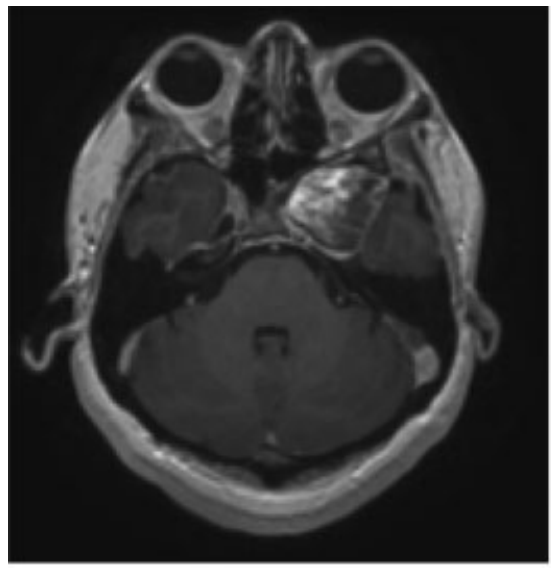

a) Axial $\mathrm{T} 1+$

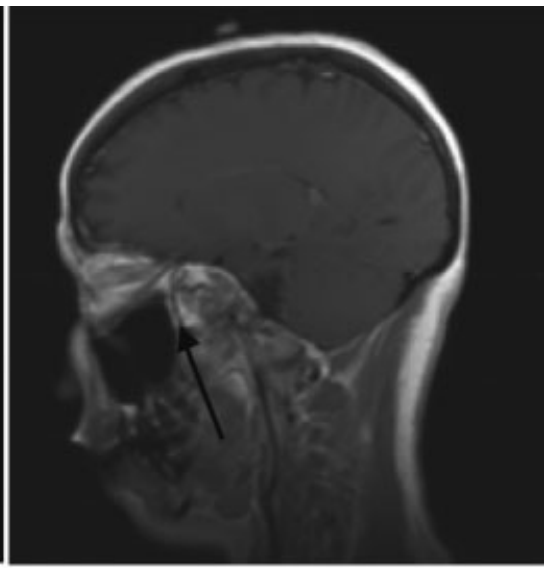

b) Sagittal T1+

Fig. 4 Twenty months postoperative magnetic resonance imaging. (A) Axial T1 postgadolinium infusion image and (B) sagittal T1 postgadolinium infusion images demonstrate reaccumulation of the cyst with representation toward the infratemporal fossa. Note the proximity to the maxillary sinus (arrow). 


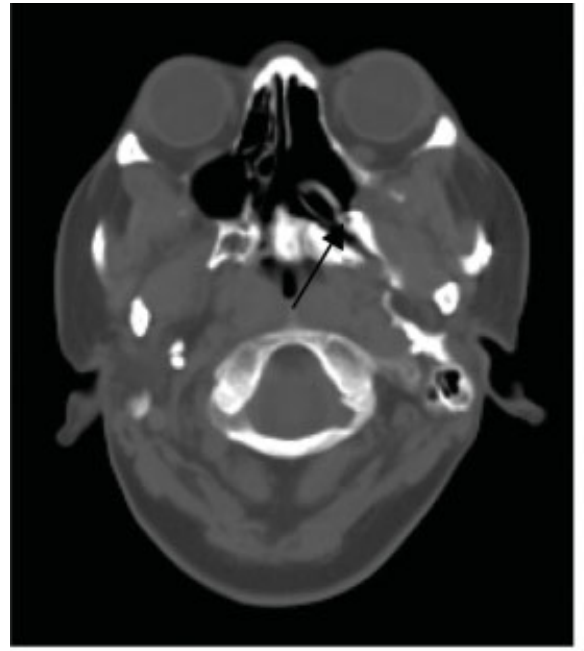

a) Axial CT (bone window)

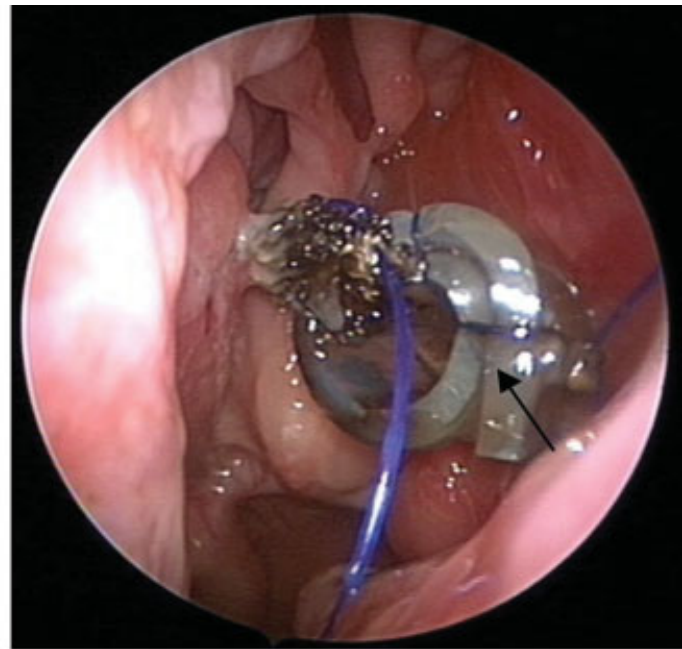

b) Silastic Stent

Fig. 5 Thirty-six months postoperative (13 months poststenting). (A) Computed tomography without contrast (bone window) shows transpterygoid stent draining the lesion into the sphenoid and maxillary sinuses (arrow). (B) Endoscopic view of the transpterygoid stent secured by Prolene suture (arrow).

Expanded endonasal approaches to the middle cranial fossa have been well described. ${ }^{22,23}$ Kassam et al used the maxillary sinus and pterygopalatine fossa as a working corridor to access lesions in Meckel cave in 40 patients and reported excellent surgical access and results with minimal morbidity. ${ }^{21}$ Given that our patient's recurrent EC occupied the anteromedial aspect of the middle cranial fossa and the adjacent infratemporal fossa, we used a similar strategy with an expanded endoscopic approach through the sphenoid and maxillary sinuses and penetrated through the medial and lateral pterygoid plates that allowed easy entry into the lesion allowing safe internal debulking and a fragmented capsular removal. We left a tract traversing the pterygoids communicating the lesion to the maxillary and sphenoid sinuses that allowed for easy drainage. However, this tract closed following a bout of local infection that resolved with antibiotics. With tumor regrowth noted on follow-up MRI studies, we elected to use a similar endoscopic strategy but left a silastic stent in the pterygoid tract permanently communicating the lesion to the maxillary sinus.

The stent is a $0.25-\mathrm{mm}$-thick silastic sheet (Dow Corning Corp., Midland, Michigan, United States) rolled into a cylinder and secured to the nasal septum with Prolene (Ethicon, Inc., Somerville, New Jersey, United States) suture. The rigidity of the silastic provides effective patency and an adequate pathway for both visualization of the cyst and evacuation of the cyst contents. This permitted easy drainage of recurrent cyst material in an outpatient setting and precluded the need for additional cranial surgery.

Silastic stenting is commonplace during lateral approaches to the petrous apex for drainage of similar lesions, but it has not been frequently described for use within the paranasal sinuses and infratemporal fossa. It is a useful strategy to consider for benign lesions with a propensity to recur in locations such as the anteromedial middle cranial fossa or infratemporal fossa that may be endoscopically accessed via a transnasal approach using the paranasal sinuses as drainage portals.

\section{Conclusion}

A transnasal transpterygoid approach can provide adequate access for intralesional debulking of a recurrent EC of the anteromedial middle cranial and infratemporal fossa, and piecemeal removal of the cyst capsule. It also avoids the morbidity of a cranial approach. Recurrence of an EC is common, and a long-term drainage strategy using a silastic stent that communicates the cyst to the maxillary sinus is a safe and effective option for management of such recurrence. Placement of the silastic stent provides endoscopic access for periodic drainage of the recurrent cyst contents in the outpatient setting with minimal discomfort or morbidity.

\section{Conflict of Interest}

The authors have no conflicts of interest or financial disclosures to report pertaining to the findings outlined in this article.

\section{References}

1 Nagasawa D, Yew A, Safaee M, et al. Clinical characteristics and diagnostic imaging of epidermoid tumors. J Clin Neurosci 2011; 18(9):1158-1162

2 Mohanty A, Venkatrama SK, Rao BR, Chandramouli BA, Jayakumar PN, Das BS. Experience with cerebellopontine angle epidermoids. Neurosurgery 1997;40(1):24-29; discussion 29-30

3 Burger PC, Scheithaur BW, Vogal FS. Surgical Pathology of the Nervous System and Its Coverings. 4th ed. New York, NY: Churchill Livingstone; 2002:91-93 
4 Muzammil S, Leong KS. A case of cerebellopontine angle epidermoid cyst presenting as trigeminal neuropathy. South Med J 2009; 102(5):534-536

5 Desai K, Nadkarni T, Bhayani R, Goel A. Cerebellopontine angle epidermoid tumor presenting with hemifacial spasms. Neurol India 2003:51(2):288-289

6 Klieb HB, Freeman BV. Trigeminal neuralgia caused by intracranial epidermoid tumour: report of a case. J Can Dent Assoc 2008;74(1): 63-65

7 Tomlinson BE, Walton JN. Granulomatous meningitis and diffuse parenchymatous degeneration of the nervous system due to an intracranial epidermoid cyst. J Neurol Neurosurg Psychiatry 1967; 30(4):341-348

8 Fox BD, Smitherman SM, Amhaz H, et al. A supratentorial, hemorrhagic, intraparenchymal epidermoid cyst. J Clin Neurosci 2009; 16(8):1101-1105

9 Link MJ, Cohen PL, Breneman JC, Tew JM Jr. Malignant squamous degeneration of a cerebellopontine angle epidermoid tumor. Case report. J Neurosurg 2002;97(5):1237-1243

10 Sirin S, Gonul E, Kahraman S, Timurkaynak E. Imaging of posterior fossa epidermoid tumors. Clin Neurol Neurosurg 2005;107(6): 461-467

11 Kallmes DF, Provenzale JM, Cloft HJ, McClendon RE. Typical and atypical MR imaging features of intracranial epidermoid tumors. AJR Am J Roentgenol 1997;169(3):883-887

12 Kumari R, Guglani B, Gupta N, Chaturvedi S. Intracranial epidermoid cyst: magnetic resonance imaging features. Neurol India 2009;57(3):359-360

13 Dechambre S, Duprez T, Lecouvet F, Raftopoulos C, Gosnard G. Diffusion-weighted MRI postoperative assessment of an epidermoid tumour in the cerebellopontine angle. Neuroradiology 1999; 41(11):829-831

14 Aribandi M, Wilson NJCT. CT and MR imaging features of intracerebral epidermoid-a rare lesion. Br J Radiol 2008;81(963):e97-e99
15 Zada G, Lin N, Ojerholm E, Ramkissoon S, Laws ER. Craniopharyngioma and other cystic epithelial lesions of the sellar region: a review of clinical, imaging, and histopathological relationships. Neurosurg Focus 2010;28(4):E4

16 Bergui M, Zhong J, Bradac GB, Sales S. Diffusion-weighted images of intracranial cyst-like lesions. Neuroradiology 2001;43(10): 824-829

17 Caldarelli M, Massimi L, Kondageski C, Di Rocco C. Intracranial midline dermoid and epidermoid cysts in children. J Neurosurg 2004;100(5, Suppl Pediatrics):473-480

18 Akhavan-Sigari R, Bellinzona M, Becker H, Samii M. Epidermoid cysts of the cerebellopontine angle with extension into the middle and anterior cranial fossae: surgical strategy and review of the literature. Acta Neurochir (Wien) 2007;149(4):429-432

19 Ahmed I, Auguste KI, Vachhrajani S, Dirks PB, Drake JM, Rutka JT. Neurosurgical management of intracranial epidermoid tumors in children. Clinical article. J Neurosurg Pediatr 2009;4(2): 91-96

20 Parikh S, Milosevic M, Wong CS, Laperriere N. Recurrent intracranial epidermoid cyst treated with radiotherapy. J Neurooncol 1995;24(3):293-297

21 Kassam AB, Prevedello DM, Carrau RL, et al. The front door to Meckel's cave: an anteromedial corridor via expanded endoscopic endonasal approach- technical considerations and clinical series. Neurosurgery 2009;64(3, Suppl):ons71-ons82; discussion ons82-ons83

22 de Oliveira E, Tedeschi H, Siqueira MG, Peace DA. The pretemporal approach to the interpeduncular and petroclival regions. Acta Neurochir (Wien) 1995;136(3-4):204-211

23 Prevedello DM, Fernandez-Miranda JC, Gardner P, et al. The transclival endoscopic endonasal approach (EEA) for prepontine neuroenteric cysts: report of two cases. Acta Neurochir (Wien) 2010; 152(7):1223-1229 